\title{
Sleep Disordered Breathing Diagnosis and Treatment During the COVID-19 Pandemic: A Nationwide Survey in China
}

This article was published in the following Dove Press journal: Nature and Science of Sleep

\author{
Xiao Lei Zhang ${ }^{1-5}$ \\ Wei Wang ${ }^{6}$ \\ Yi Xiao ${ }^{7}$
}

On behalf of the members of the Assembly of Sleep Disordered Breathing of the Chinese Thoracic Society

'Department of Pulmonary and Critical Care Medicine, Center of Respiratory Medicine, China-Japan Friendship Hospital, Beijing, People's Republic of China; ${ }^{2}$ National Clinical Research Center for Respiratory Diseases, Beijing, People's Republic of China; ${ }^{3}$ The Graduate School of Peking Union Medical College, Chinese Academy of Medical Science and Peking Union Medical College, Beijing, People's Republic of China; ${ }^{4}$ Capital Medical University, Beijing, People's Republic of China; ${ }^{5}$ Peking University Health Science Center, Beijing, People's Republic of China; ${ }^{6}$ Department of Pulmonary and Critical Care Medicine, The First Affiliated Hospital of Chinese Medical University, Shenyang, People's Republic of China; ${ }^{7}$ Department of Respiratory Medicine, Peking Union Medical College Hospital, Chinese Academy of Medical Sciences \& Peking Union Medical College, Beijing, People's Republic of China

Correspondence: $Y_{i}$ Xiao Department of Respiratory Medicine, Peking Union Medical College Hospital, Chinese Academy of Medical Sciences \& Peking Union Medical College, No. I Shuaifuyuan Street, Dongcheng District, Beijing 100730, People's Republic of China Tel +86-13910158830

Email xiaoyipumch@sina.com
Background and Objective: The coronavirus disease 2019 (COVID-19) pandemic has markedly impacted the distribution of medical resources and healthcare delivery systems. The objective of this study was to investigate the influence of the pandemic on the diagnosis and treatment of sleep-disordered breathing (SDB) in China.

Methods: A retrospective online survey of sleep centers from the assembly of SDB of the Chinese Thoracic Society was conducted from July 1 to July 20, 2020. The questionnaire focused on four main aspects: 1) general information about the centers; 2) changes in SDB management activities, including patient volumes, diagnostic and positive airway pressure (PAP) titration procedures, and follow-up methods, from February to June 2020, compared with before; 3) the application of telemedicine and sleep specialists' self-assessments of knowledge and their perspectives on telemedicine; and 4) changes in medical staff active in sleep services during the pandemic compared with before.

Results: Fifty-three (96\%) of the sleep centers responded to the survey. During the early stage of the outbreak, SDB medical services were dramatically reduced to $5-10 \%$ of the preepidemic level, and laboratory-based polysomnograms and manual titration were almost cancelled. With the subsidence of COVID-19, SDB medical services gradually resumed to approximately half of the pre-pandemic level by June. However, a second wave of COVID19 in Beijing significantly reduced the recovery of SDB services. The application of polygraphy has increased significantly. Home-initiated PAP and telemedicine still accounted for a small part of SDB management during the pandemic.

Conclusion: The COVID-19 pandemic has greatly challenged SDB management in China. Polygraphy played a major role in SDB diagnosis during the pandemic. Home-based SDB management and telemedicine have not been well implemented. The second surge of COVID-19 in Beijing cut back on the recovering SDB service to the early outbreak level, which may give us an impetus to restructure our sleep health service.

Keywords: COVID-19, sleep disordered breathing, polygraphy, surveys and questionnaires

\section{Introduction}

The 2019 coronavirus disease (COVID-19), which was first detected in Wuhan, China, has spread across the world in an unprecedented way and already affected millions of people. ${ }^{1}$ This pandemic has significantly altered the operation of healthcare systems, and sleep medicine's clinical and financial landscape has also been vastly affected. Due to the reallocation of health-care resources from elective care to urgent visits and the concerns about the potential aerosolization spread of the virus by positive airway pressure (PAP) therapy, as well as the possible 
contamination of PAP and sleep study devices, most sleep services suspended routine office visits, in lab titration and polysomnography (PSG) during the early stage of the pandemic's surge. With the implementation of the social distancing policy and quarantine rules, severe in-hospital cases of COVID-19 are stable or declining in most nations; however, new cases are still escalating everyday worldwide. It is difficult to predict if or when another major surge will return. Considering the possibility of the pandemic continuing for a relatively long period of time in the future, sleep health systems should balance the need to provide necessary services while minimizing the risk of transmission. ${ }^{2}$ The assembly of sleep-disordered breathing (SDB) of the Chinese Thoracic Society (CTS, http://www. csrd.org.cn) issued an expert consensus on sleep study and PAP therapy during the pandemic, with the effort to gradually restore normal sleep care delivery together with strict epidemic prevention and control. ${ }^{3}$

The patient population and disease burden of SDB are quite high in China. ${ }^{4,5}$ The major comorbidities of SDB, including obesity, hypertension, cardiovascular diseases, diabetes, and poor sleep quality, are considered to be major risk factors for adverse outcomes of the COVID19 disease. $^{6,7}$ China is one of the first nations to experience the early surge and later subsidence of this pandemic in the current stage. As in many other fields, sleep health delivery is resuming gradually to satisfy the ongoing health needs that have been postponed. In the present study, we investigate the influence of the COVID-19 epidemic on the management of SDB in China during the process of the outbreak, which may help the management of SDB to reflect on the lessons we have learned and to be better prepared, should another global outbreak occur again.

\section{Materials and Methods}

A retrospective online survey of sleep centers from the assembly of SDB by the CTS (http://www.csrd.org.cn), a well-established organization of sleep centers in 23 provinces throughout China, was performed from July 1 to 20, 2020. The questionnaire was developed and collected using Wenjuanxing (https:/www.wjx.cn), an online data collection program. The survey included 18 questions (fillin-the-blank and single-or multiple-choice questions, Appendix) and focused on four main topics: (1) general information about the centers, such as location, clinical affiliation, patient spectrum and the number of independent sleep study beds; (2) changes in SDB management activities, including patient volumes, diagnostic and PAP titration procedures, and follow-up methods, during the COVID-19 pandemic compared with before (0-100\%); (3) the application of telemedicine for SDB diagnosis, PAP titration and follow-up during the pandemic and before; and (4) changes in medical staff active in sleep services during the pandemic compared with before ( 0 -$100 \%$, including physicians, nurses/technicians and visiting personnel in the training program). For the third topic, the mode of telemedicine (center to center or center to patient), the proportion of patients using telemedicine for follow-ups, and the sleep specialists' self-assessments of knowledge and their perspectives on telemedicine were addressed. For the fourth topic, the number of sleep care staff infected with COVID-19 was also investigated. All questions were mandatory, and the replies were only sent and received if the respondent reached the end of the questionnaire. No approval was obtained from an institutional review board because the survey was anonymous, and no patient data were included.

The survey was sent to the medical directors of the sleep centers, and the questionnaires were assessed per each center. The response from the directors was only considered valid when more than one response was received from the same center. A total of 53 sleep centers from 23 provinces/autonomous regions/municipalities covering six administrative divisions responded to the survey (Figure 1). Three reminders were sent until replies were received, and the response rate of the survey was $96 \%$. Most centers were affiliated with the pulmonary department, and nearly two-thirds of the centers were mainly focused on the management of SDB. More than $40 \%$ of the sleep centers had 4-6 sleep study beds, and approximately one-quarter of sleep centers had fewer than 3 or more than 7 sleep study beds (Table 1).

\section{Statistical Analysis}

Data are presented as the median and interquartile range for numerical variables with a skewed distribution. Comparisons between groups were determined using the Kruskal-Wallis one-way analysis, and a chi-square test or Fisher's exact test was used for categorical data. Spearman correlation coefficients were used to determine the association of potential predictor variables (clinical affiliation, patient spectrum, number of beds, local epidemic condition, routine practice beforehand, medical staff still active in the sleep service) with changes in patient volume and the mode of SDB diagnosis and PAP titration during 


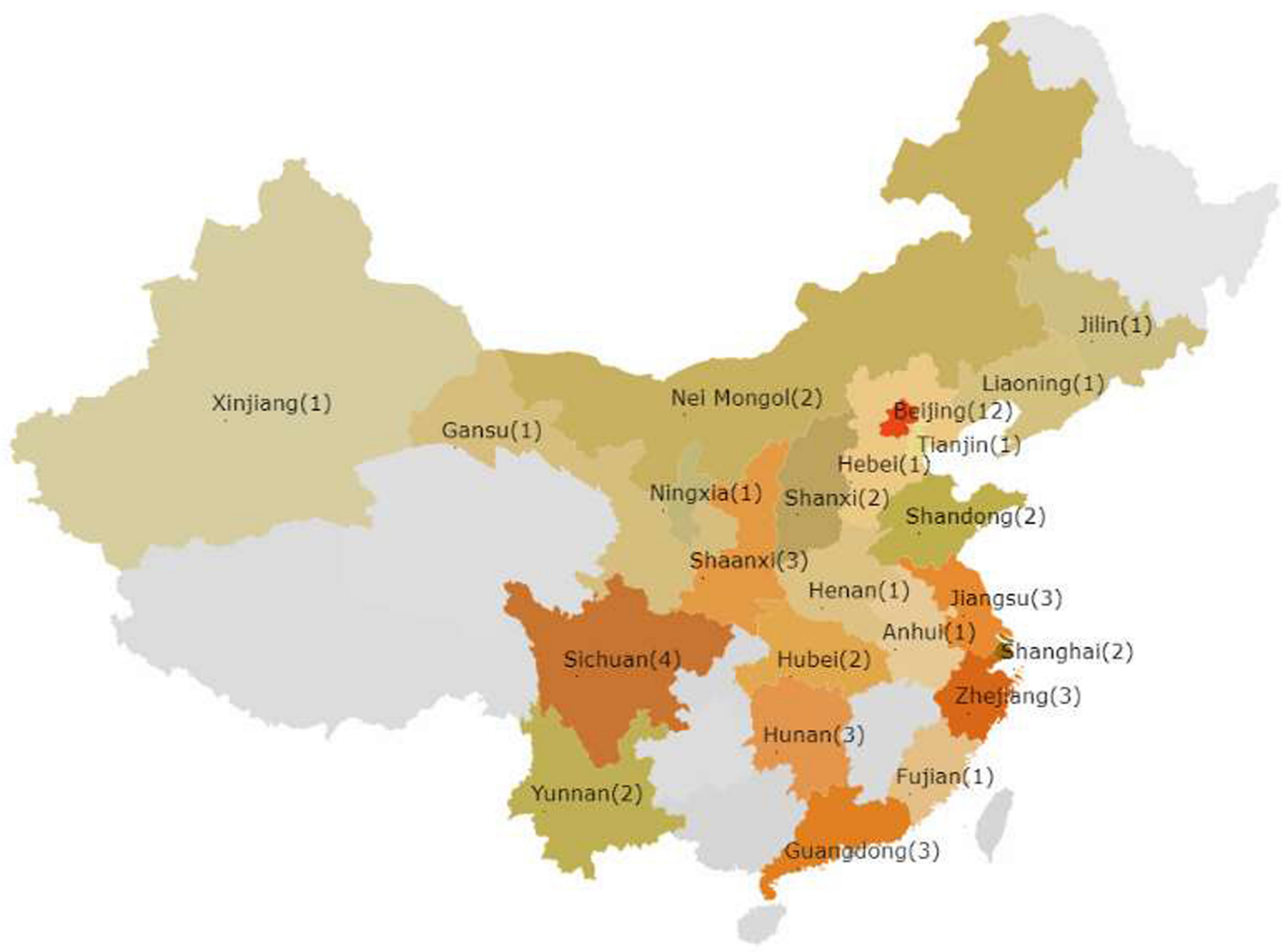

Figure I The distribution of the sleep centers that responded to this survey.

different periods of the pandemic. Predictor variables with $\mathrm{p}<0.10$, according to the bivariate analysis, were selected for multivariate regression analysis. A value of $\mathrm{p}<0.05$ was considered statistically significant. All analyses were conducted with SPSS 22.0 (SPSS Inc., Chicago, Illinois, United States).

\section{Results}

\section{Diagnostic Activities}

Patient volume in the sleep study decreased $90 \%$ from February to March and gradually increased to $50 \%$ and $60 \%$ of the pre-epidemic level from April to June. Prior to the pandemic, the ratio of in-lab PSG and home polygraphy was nearly $1: 1$ in the surveyed centers. During the early stage of the pandemic, almost all the surveyed centers cancelled in-lab PSG and converted to polygraphy. The preponderance of polygraphy persisted until the later period of the pandemic (Table 2, Figure 2). According to adjusted analysis, the number of beds in the surveyed center was associated with the total number of sleep studies during the pandemic. In June, the local epidemic condition was also independently associated with the total number of sleep studies. The proportion of PSG from April to June was associated with the proportion of PSG before, and no baseline characteristics of the surveyed sleep centers were associated with the proportion of PSG in February to March (Table 3).

\section{PAP Titration and Initiation Activities}

The number of patients receiving PAP titration and initiation declined substantially during the pandemic, with an overall reduction of $95 \%$ yielding from February to March, which slowly recovered to half of the preepidemic volume in June. Almost all the sleep centers halted manual titration in the early stage of the pandemic and substituted it using home autotitration and initiation. However, laboratory-based titration (manual or auto) was 
Table I Characteristics of the Surveyed Sleep Centers

\begin{tabular}{|c|c|}
\hline Number of Centers (Total) & 53 \\
\hline \multicolumn{2}{|l|}{ Region of centers } \\
\hline North China & 18 \\
\hline North East China & 2 \\
\hline East China & 12 \\
\hline Middle South China & 9 \\
\hline South west China & 6 \\
\hline North west China & 6 \\
\hline \multicolumn{2}{|l|}{ Clinical affiliation of the centers } \\
\hline Pulmonary and critical care department & 38 \\
\hline Neurology department & 2 \\
\hline Otorhinolaryngology department & 5 \\
\hline Independent sleep center & 8 \\
\hline \multicolumn{2}{|l|}{ Patient spectrum of the centers } \\
\hline Focus on sleep disordered breathing & 35 \\
\hline Entire spectrum of sleep/wake disorders & 18 \\
\hline \multicolumn{2}{|l|}{ Number of sleep study bed } \\
\hline $0-3$ & 15 \\
\hline $4-6$ & 23 \\
\hline$\geq 7$ & 15 \\
\hline Perspective on telemedicine (increase/no change/decrease/ & $34 / 1 / 5 /$ \\
\hline uncertain) & 13 \\
\hline Self-assessment of knowledge on telemedicine (very good/ & $8 / 28 /$ \\
\hline quite good/not too much/no idea) & $15 / 2$ \\
\hline \multicolumn{2}{|l|}{ Obstacles for telemedicine } \\
\hline Technology and equipment & 34 \\
\hline Health care policies and regulations & 33 \\
\hline Medical insurance payment system & 40 \\
\hline Lack of personnel & 10 \\
\hline
\end{tabular}

Notes: The mainland China is divided into six administrative zones, which are North China (Beijing, Tianjin, Hebei, Shanxi, Nei Mongo), North East China (Liaoning, Jilin, Heilongjiang), East China (Shanghai, Jiangsu, Zhejiang, Jiangxi, Anhui, Fujian, Shandong), Middle South China (Henan, Hubei, Hunan, Guangdong, Guangxi, Hainan), South west China (Chongqing, Sichuan, Guizhou, Yunnan, Tibet) and North west China (Shanxi, Gansu, Qinghai, Ningxia, Xinjiang).

still the primary procedure for PAP initiation during the pandemic (Table 2, Figure 3). The total number of PAP titrations was associated with the technicians working in the sleep center from April to June. The proportion of home autotitration during the pandemic was associated with the proportion of home autotitration before (Table 4).

\section{Follow-Up Procedures}

Prior to the pandemic, in-clinic visits were one of the main follow-up modes for the surveyed sleep centers, but they decreased substantially in February and March, with more patients lost to follow up during this period. Although the proportion of in-clinic visits increased from April to June, it still has not resumed to the prepandemic level (Table 2).

\section{Telemedicine}

Prior to the pandemic, telemedicine for SDB diagnosis was practiced in 15 of the 53 surveyed sleep centers. Five centers cancelled the practice in February and March due to a lack of sleep service personnel, and the number of sleep centers providing this service almost maintained the pre-epidemic level from April to June. The modes of telemedicine for SDB diagnosis were mainly performed as center to center $(\mathrm{C} 2 \mathrm{C})$. Telemedicine for SDB treatment was performed in 12 centers using both $\mathrm{C} 2 \mathrm{C}$ and center to patients (C2P) modes before the pandemic. Three centers cancelled this service in February and March, and 5 to 6 centers resumed or started this service in April to June. Nearly one-third of the surveyed sleep centers utilized telemedicine for follow-up before the pandemic, and the number of centers providing this service did not change significantly during the pandemic. Telemedicine only accounted for a small part of the follow up in centers providing this service during the pandemic (Table 2).

Nearly two-thirds of the responders held a positive view about the perspective of telemedicine for SDB management and thought their knowledge of telemedicine was very good or quite good. Insurance policy limitations were listed as the primary bottleneck (40/53) for the implementation of telemedicine for SDB management, and nearly two-thirds of responders thought that technology and relevant health-care policies and regulations were the other two main obstacles, while 10 responders considered a lack of personnel to be a barrier for telemedicine services (Table 1).

\section{Sleep Care Staffing}

The number of physicians and nurses/technicians in sleep medicine services reduced to $50 \%$ and $60 \%$, respectively, during the pandemic compared to pre-pandemic levels. In all surveyed sleep centers, no COVID-19-infected cases had been reported among the sleep service personnel. Most sleep training programs were halted during the early stage of the pandemic and marginally resumed in some areas in June (Table 2).

\section{Impact of the Second COVID-19 Wave in Beijing}

In June, the second COVID-19 wave hit Beijing, and 335 new COVID-19 cases were identified. The recovery of the 
Table 2 Changes in Sleep Service Activities During the COVID-19 Pandemic

\begin{tabular}{|c|c|c|c|c|}
\hline & $\begin{array}{l}\text { Pre- } \\
\text { Pandemic }\end{array}$ & Feb-Mar & Apr-May & Jun \\
\hline Patient volume of sleep study (\%) & 100 & $10(0,20)$ & $50(30,69)^{\mathrm{b}}$ & $60(30,80)^{b}$ \\
\hline \multicolumn{5}{|l|}{ Diagnostic procedures (\%) } \\
\hline Polysomnography & $50(32,80)$ & $0(0,10)^{a}$ & $25(10,50)^{a, b}$ & $30(10,60)^{a, b}$ \\
\hline Polygraphy & $50(20,65)$ & $90(20,100)^{\mathrm{a}}$ & $70(40,90)^{a}$ & $64(25,90)$ \\
\hline Empiric treatment without study & $0(0,7.5)$ & $0(0,10)$ & $0(0,10)$ & $0(0,5)$ \\
\hline Patient volume of PAP titration (\%) & 100 & $5(0,20)$ & $30(10,65)^{b}$ & $50(10,80)^{b}$ \\
\hline \multicolumn{5}{|l|}{ Titration procedures (\%) } \\
\hline In-lab manual titration & $20(10,60)$ & $0(0,10)^{\mathrm{a}}$ & $10(0,32)^{a, b}$ & $10(0,37)^{\mathrm{b}}$ \\
\hline In-lab autotitration & $50(20,85)$ & $50(0,92)$ & $50(8,88)$ & $55(10,89)$ \\
\hline Home autotitration & $5(0,20)$ & $40(0,96)$ & $5(0,50)$ & $5(0,48)$ \\
\hline \multicolumn{5}{|l|}{ Follow-up method (\%) } \\
\hline Clinic & $30(20,50)$ & $0(0,10)^{a}$ & $20(10,30)^{a, b}$ & $20(10,30)^{a, b}$ \\
\hline Telephone & $40(20,50)$ & $50(9,90)$ & $55(20,77)$ & $50(20,75)$ \\
\hline Telemedicine & $0(0,10)$ & $0(0,25)$ & $0(0,10)$ & $0(0,10)$ \\
\hline Without follow-up & $25(5,40)$ & $40(10,70)^{\mathrm{a}}$ & $30(10,53)$ & $30(20,55)$ \\
\hline Number of centers using telemedicine for diagnosis $(n)$ & 15 & 10 & 16 & 16 \\
\hline $\mathrm{C} 2 \mathrm{C}$ & 11 & 7 & 12 & 12 \\
\hline $\mathrm{C} 2 \mathrm{P}$ & 5 & 3 & 5 & 5 \\
\hline Number of centers using telemedicine for PAP titration $(n)$ & 12 & 9 & 14 & 15 \\
\hline $\mathrm{C} 2 \mathrm{C}$ & 7 & 4 & 7 & 9 \\
\hline $\mathrm{C} 2 \mathrm{P}$ & 5 & 5 & 7 & 6 \\
\hline Number of centers using telemedicine for follow up ( $n$ ) & 17 & 13 & 16 & 17 \\
\hline $\begin{array}{l}\text { Proportion of patients using telemedicine for follow up in the centers } \\
\text { practicing this service (\%) }\end{array}$ & $10(10,23)$ & $20(10,40)$ & $20(15,40)$ & $10(10,30)$ \\
\hline \multicolumn{5}{|l|}{ Medical staff changes (\%) } \\
\hline Physician & $100 \%$ & $50(30,60)$ & $50(30,83)$ & $50(30,100)$ \\
\hline Technician and nurse & $100 \%$ & $50(30,78)$ & $60(45,80)$ & $60(43,80)$ \\
\hline Physician/technician/nurse in training & $100 \%$ & $0(0,0)$ & $0(0,18)$ & $0(0,23)^{\mathrm{b}}$ \\
\hline
\end{tabular}

Notes: ${ }^{a} \mathrm{p}<0.05$ compared with pre-pandemic, ${ }^{\mathrm{b}} \mathrm{p}<0.05$ compared with February-March. Data are presented as the median and interquartile range for numerical variables with a skewed distribution. Comparisons between groups were determined by the Kruskal-Wallis one-way analysis. A value of $p<0.05$ was considered statistically significant. The patient volumes for sleep study, PAP titration and medical staff before the pandemic was defined as $100 \%$.

Abbreviations: Apr, April; C2C, center to center; C2P, center to patient; Feb, February; Jun, June; Mar, March; PAP, positive airway pressure.

sleep medicine service was forced to press the pause button. The recovery for the diagnostic test $[30 \%(23 \%$, $50 \%)$ vs $70 \%(45 \%, 85 \%), \mathrm{p}=0.001]$, PAP titration $[18 \%$ $(1 \%, 48 \%)$ vs $50 \%(18 \%, 85 \%), \mathrm{p}=0.004]$ and in-lab PSG $[8 \%(0 \%, 19 \%)$ vs $36 \%(13 \%, 68 \%), p=0.006]$ was significantly slower in the 12 sleep centers in Beijing, compared to the 41 centers outside of Beijing. In June, the amount of in-lab PSG and manual titration were almost cut to the level of February to March (Figure 4).

\section{Discussion}

The COVID-19 pandemic has had a significant impact on the distribution of medical resources and healthcare delivery systems worldwide. According to this retrospective survey, SDB management in China was fundamentally altered by the pandemic. First, during the early surge of the outbreak, SDB medical services were sharply reduced to $5-10 \%$ of the pre-epidemic level. Laboratory-based PSG, manual titration and in-clinic follow-up were almost cancelled. With the subsidence of COVID-19, SDB medical services gradually resumed to approximately half of the pre-pandemic level by June. Polygraphy became the preponderant mode of SDB diagnosis; however, laboratory-based titration (manual or auto) was still the main PAP initiation procedure during the pandemic. Second, a second 


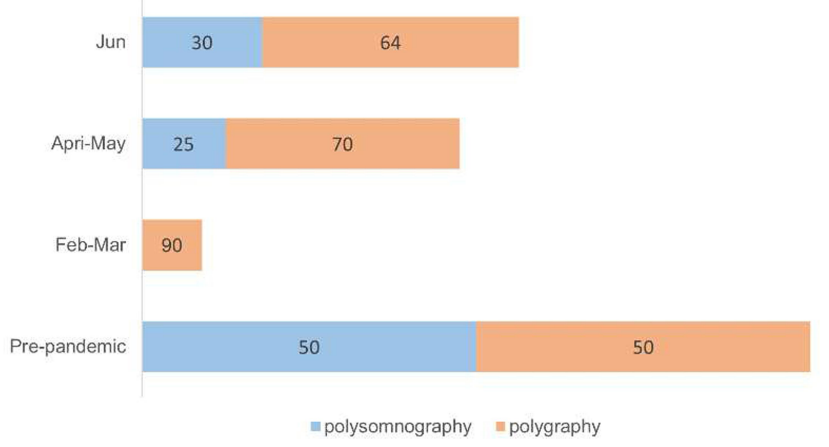

Figure 2 Changes in patient volume and mode of sleep study during the pandemic. The length of the column represents the number of sleep studies and the number on the column represents the proportion (median) of sleep study procedure (blue column for polysomnography and orange column for polygraphy).

wave of COVID-19 halted the recovery of SDB services in Beijing and cut back PSG and in-lab PAP titrations to the early outbreak level. Third, although most sleep specialists held positive views on

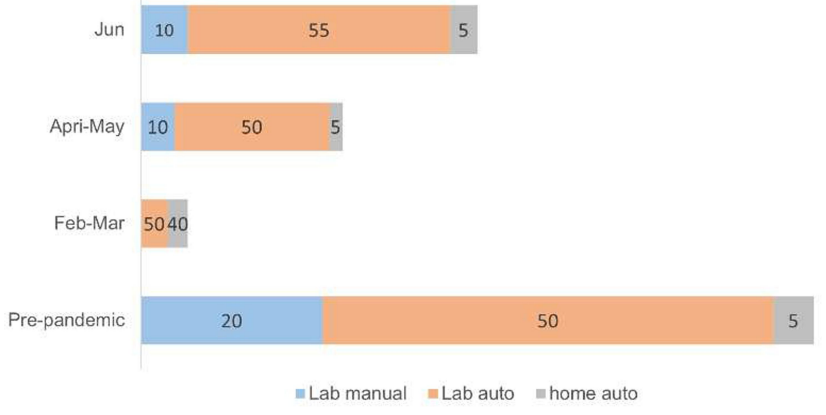

Figure 3 Changes in patient volume and mode of positive airway pressure titration. The length of the column represents the number of titrations and the number on the column represents the proportion (median) of titration procedure (blue column for lab manual titration, orange column for lab auto titration, and grey column for home auto titration).

telemedicine, it was only practiced in a small portion of the surveyed sleep centers. Fourth, the sleep medicine training program was also markedly affected by the epidemic.

Table 3 Correlates of the Number of Sleep Tests and Proportion of PSG During Different Periods of the Pandemic

\begin{tabular}{|c|c|c|c|c|c|c|}
\hline Unadjusted Analysis & $\begin{array}{l}\text { Feb-Mar Sleep } \\
\text { Test }(r, p)\end{array}$ & $\begin{array}{l}\text { Feb-Mar } \\
\text { PSG }(r, p)\end{array}$ & $\begin{array}{l}\text { Apr-May Sleep } \\
\text { Test }(r, p)\end{array}$ & $\begin{array}{l}\text { Apr-May } \\
\text { PSG }(r, p)\end{array}$ & $\begin{array}{l}\text { June Sleep } \\
\text { test }(r, p)\end{array}$ & $\begin{array}{l}\text { June PSG } \\
(r, p)\end{array}$ \\
\hline Clinical affiliation & $\begin{array}{l}0.255 \\
0.065\end{array}$ & $\begin{array}{l}0.108 \\
0.440\end{array}$ & $\begin{array}{l}0.223 \\
0.109\end{array}$ & $\begin{array}{l}0.215 \\
0.121\end{array}$ & $\begin{array}{l}0.217 \\
0.119\end{array}$ & $\begin{array}{l}0.187 \\
0.180\end{array}$ \\
\hline Patient spectrum & $\begin{array}{l}0.344 \\
0.012\end{array}$ & $\begin{array}{l}0.123 \\
0.382\end{array}$ & $\begin{array}{l}0.339 \\
0.013\end{array}$ & $\begin{array}{l}0.241 \\
0.082\end{array}$ & $\begin{array}{l}0.332 \\
0.015\end{array}$ & $\begin{array}{l}0.176 \\
0.208\end{array}$ \\
\hline Number of beds & $\begin{array}{l}0.370 \\
0.006\end{array}$ & $\begin{array}{l}0.197 \\
0.158\end{array}$ & $\begin{array}{l}0.374 \\
0.006\end{array}$ & $\begin{array}{l}0.180 \\
0.197\end{array}$ & $\begin{array}{l}0.346 \\
0.011\end{array}$ & $\begin{array}{l}0.121 \\
0.389\end{array}$ \\
\hline $\begin{array}{l}\text { Local epidemic condition } \\
\text { during this period }\end{array}$ & $\begin{array}{l}-0.235 \\
0.090\end{array}$ & $\begin{array}{l}-0.255 \\
0.066\end{array}$ & $\begin{array}{l}0.236 \\
0.089\end{array}$ & $\begin{array}{l}0.172 \\
0.217\end{array}$ & $\begin{array}{l}0.343 \\
0.012\end{array}$ & $\begin{array}{l}0.223 \\
0.108\end{array}$ \\
\hline $\begin{array}{l}\text { Proportion of PSG } \\
\text { beforehand }\end{array}$ & $\begin{array}{l}-0.039 \\
0.780\end{array}$ & $\begin{array}{l}0.216 \\
0.120\end{array}$ & $\begin{array}{l}0.040 \\
0.774\end{array}$ & $\begin{array}{l}0.534 \\
<0.001\end{array}$ & $\begin{array}{l}0.016 \\
0.910\end{array}$ & $\begin{array}{l}0.596 \\
<0.001\end{array}$ \\
\hline Physicians during this period & $\begin{array}{l}0.058 \\
0.692\end{array}$ & $\begin{array}{l}-0.220 \\
0.129\end{array}$ & $\begin{array}{l}0.118 \\
0.399\end{array}$ & $\begin{array}{l}-0.152 \\
0.277\end{array}$ & $\begin{array}{l}-0.002 \\
0.986\end{array}$ & $\begin{array}{l}-0.193 \\
0.167\end{array}$ \\
\hline Technicians during this period & $\begin{array}{l}0.075 \\
0.609\end{array}$ & $\begin{array}{l}0.024 \\
0.871\end{array}$ & $\begin{array}{l}0.258 \\
0.063\end{array}$ & $\begin{array}{l}-0.060 \\
0.670\end{array}$ & $\begin{array}{l}0.132 \\
0.346\end{array}$ & $\begin{array}{l}-0.153 \\
0.274\end{array}$ \\
\hline \multicolumn{7}{|l|}{ Adjusted analysis (Beta, $P$ ) } \\
\hline Patient spectrum & $\begin{array}{l}0.094 \\
0.570\end{array}$ & $\mathrm{~N} / \mathrm{A}$ & $\begin{array}{l}0.184 \\
0.208\end{array}$ & $\mathrm{~N} / \mathrm{A}$ & $\begin{array}{l}12.216 \\
0.216\end{array}$ & $\mathrm{~N} / \mathrm{A}$ \\
\hline Number of beds & $\begin{array}{l}0.036 \\
0.008\end{array}$ & N/A & $\begin{array}{l}0.372 \\
0.007\end{array}$ & N/A & $\begin{array}{l}13.927 \\
0.029\end{array}$ & $\mathrm{~N} / \mathrm{A}$ \\
\hline $\begin{array}{l}\text { Local epidemic condition } \\
\text { during this period }\end{array}$ & $\begin{array}{l}-0.082 \\
0.209\end{array}$ & $\mathrm{~N} / \mathrm{A}$ & $\begin{array}{l}-0.046 \\
0.299\end{array}$ & $\mathrm{~N} / \mathrm{A}$ & $\begin{array}{l}10.924 \\
0.004\end{array}$ & $\mathrm{~N} / \mathrm{A}$ \\
\hline
\end{tabular}

Notes: The epidemic condition was classified into 7 levels according to the new emerging COVID-19 cases in the local province: level I I 10,000, level $2=1000-9999$, level $3=500-999$, level $4=100-499$, level $5=10-99$, level $6=1-9$, level $7=0$.

Abbreviations: Apr, April; C2C, center to center; C2P, center to patient; Feb, February; Jun, June; Mar, March; PSG, polysomnography. 
Table 4 Correlates of the Number of PAP Titration and Proportion of Home Autotitration During Different Periods of the Pandemic

\begin{tabular}{|c|c|c|c|c|c|c|}
\hline Unadjusted Analysis & $\begin{array}{l}\text { Feb-Mar PAP } \\
\text { Titration }(r, p)\end{array}$ & $\begin{array}{l}\text { Feb-Mar Home } \\
\text { Auto }(r, p)\end{array}$ & $\begin{array}{l}\text { Apr-May PAP } \\
\text { Titration }(r, p)\end{array}$ & $\begin{array}{l}\text { Apr-May Home } \\
\text { Auto }(r, p)\end{array}$ & $\begin{array}{l}\text { June PAP } \\
\text { Titration }(r, p)\end{array}$ & $\begin{array}{l}\text { June Home } \\
\text { Auto }(r, p)\end{array}$ \\
\hline Clinical affiliation & $\begin{array}{l}0.267 \\
0.154\end{array}$ & $\begin{array}{l}0.114 \\
0.428\end{array}$ & $\begin{array}{l}-0.010 \\
0.941\end{array}$ & $\begin{array}{l}0.116 \\
0.418\end{array}$ & $\begin{array}{l}0.040 \\
0.778\end{array}$ & $\begin{array}{l}0.032 \\
0.817\end{array}$ \\
\hline Patient spectrum & $\begin{array}{l}0.013 \\
0.944\end{array}$ & $\begin{array}{l}0.097 \\
0.496\end{array}$ & $\begin{array}{l}0.192 \\
0.168\end{array}$ & $\begin{array}{l}0.117 \\
0.412\end{array}$ & $\begin{array}{l}0.267 \\
0.054\end{array}$ & $\begin{array}{l}0.147 \\
0.292\end{array}$ \\
\hline Number of beds & $\begin{array}{l}-0.179 \\
0.344\end{array}$ & $\begin{array}{l}-0.166 \\
0.243\end{array}$ & $\begin{array}{l}0.136 \\
0.332\end{array}$ & $\begin{array}{l}-0.108 \\
0.452\end{array}$ & $\begin{array}{l}0.150 \\
0.285\end{array}$ & $\begin{array}{l}-0.123 \\
0.380\end{array}$ \\
\hline $\begin{array}{l}\text { Local epidemic condition } \\
\text { during this period }\end{array}$ & $\begin{array}{l}0.016 \\
0.935\end{array}$ & $\begin{array}{l}0.034 \\
0.811\end{array}$ & $\begin{array}{l}-0.049 \\
0.728\end{array}$ & $\begin{array}{l}-0.016 \\
0.910\end{array}$ & $\begin{array}{l}0.289 \\
0.036\end{array}$ & $\begin{array}{l}-0.011 \\
0.938\end{array}$ \\
\hline $\begin{array}{l}\text { Proportion of home } \\
\text { autotitration beforehand }\end{array}$ & $\begin{array}{l}0.015 \\
0.915\end{array}$ & $\begin{array}{l}0.755 \\
<0.001\end{array}$ & $\begin{array}{l}-0.089 \\
0.533\end{array}$ & $\begin{array}{l}0.721 \\
<0.001\end{array}$ & $\begin{array}{l}-0.182 \\
0.201\end{array}$ & $\begin{array}{l}0.827 \\
<0.001\end{array}$ \\
\hline $\begin{array}{l}\text { Physicians during this } \\
\text { period }\end{array}$ & $\begin{array}{l}0.007 \\
0.960\end{array}$ & $\begin{array}{l}0.008 \\
0.959\end{array}$ & $\begin{array}{l}0.231 \\
0.105\end{array}$ & $\begin{array}{l}0.151 \\
0.289\end{array}$ & $\begin{array}{l}0.067 \\
0.636\end{array}$ & $\begin{array}{l}0.176 \\
0.209\end{array}$ \\
\hline $\begin{array}{l}\text { Technicians during this } \\
\text { period }\end{array}$ & $\begin{array}{l}-0.052 \\
0.722\end{array}$ & $\begin{array}{l}-0.312 \\
0.033\end{array}$ & $\begin{array}{l}0.310 \\
0.024\end{array}$ & $\begin{array}{l}0.034 \\
0.812\end{array}$ & $\begin{array}{l}0.297 \\
0.031\end{array}$ & $\begin{array}{l}0.056 \\
0.692\end{array}$ \\
\hline \multicolumn{7}{|l|}{ Adjusted analysis (Beta, P) } \\
\hline $\begin{array}{l}\text { Local epidemic } \\
\text { condition during this } \\
\text { period }\end{array}$ & N/A & $\mathrm{N} / \mathrm{A}$ & $N / A$ & $N / A$ & $\begin{array}{l}-0.020 \\
0.852\end{array}$ & $N / A$ \\
\hline $\begin{array}{l}\text { Proportion of home } \\
\text { autotitration } \\
\text { beforehand }\end{array}$ & $\mathrm{N} / \mathrm{A}$ & $\begin{array}{l}1.318 \\
<0.001\end{array}$ & $\mathrm{~N} / \mathrm{A}$ & N/A & $\mathrm{N} / \mathrm{A}$ & $N / A$ \\
\hline $\begin{array}{l}\text { Technicians during this } \\
\text { period }\end{array}$ & $N / A$ & $\begin{array}{l}-0.181 \\
0.215\end{array}$ & $\mathrm{~N} / \mathrm{A}$ & $\mathrm{N} / \mathrm{A}$ & $\begin{array}{l}1.165 \\
<0.001\end{array}$ & N/A \\
\hline
\end{tabular}

Notes: The epidemic condition was classified into 7 levels according to the new emerging COVID-19 cases in the local province: level $1 \geq 10,000$, level $2=1000-9999$, level $3=500-999$, level $4=100-499$, level $5=10-99$, level $6=1-9$, level $7=0$.

Abbreviations: Apr, April; C2C, center to center; C2P, center to patient; Feb, February; Jun, June; Mar, March; PAP, positive airway pressure.

In the beginning of 2020, COVID-19 rapidly spread to 31 provinces throughout China after the first outbreak in Wuhan. Because sleep studies and PAP therapy can increase the risk of exposure and transmission of new coronaviruses to medical staff and patients, the SDB assembly of CTS issued the expert consensus on sleep studies and PAP therapy. ${ }^{3}$ It is strongly recommended that the indications for sleep studies and PAP be strictly defined according to the local epidemic situation and the specific conditions (infection control, routine management strategies and available sleep service staff) of the sleep lab. In the present survey, we found that the changes in the patient volume of the sleep study were associated with the number of beds in the surveyed centers, and the local epidemic condition was also an independent predictor of the number of sleep studies in June. Possible reasons may be that in the early stage of the pandemic, most provinces in China were listed as high-risk areas and sleep centers adopted strict infection control strategies. For sleep centers with larger spaces (more beds), it is relatively easier to separate or reregulate the functional divisions (clean area, contaminated area and half contaminated area) and allow them to resume certain activities more quickly. With the subsidence of the epidemic and further understanding of the disease, most sleep centers adopt more reasonable infection control strategies according to local epidemic conditions.

Prior to the pandemic, half of the SDB diagnosis was performed with in-lab PSG and half with polygraphy in the surveyed centers. The differences in the proportion of these two diagnostic modes among the sleep centers may be related to space, staffing and patient spectrum. During the pandemic, polygraphy became the mainstay of sleep testing 


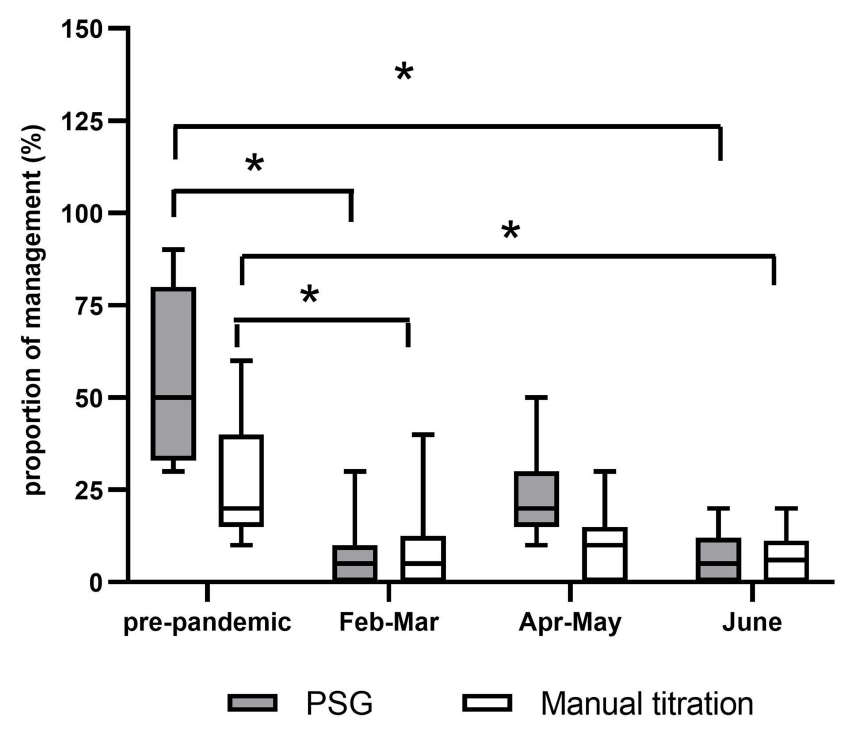

Figure 4 Changes in laboratory polysomnography and manual titration in the 12 sleep centers in Beijing during the pandemic. ${ }^{*} p<0.05$ compared with the prepandemic level.

in all sleep labs because most in-lab services were forced to shut down, especially in the early stage of the outbreak. The sleep labs that majored in PSG were the most heavily affected. In the early surge of the pandemic, the proportion of PSG was not associated with the baseline characteristics and local epidemic situation of the sleep center, and the diagnostic mode was becoming more correlated with prior routine in the later stage of the pandemic. PSG has been the central focus of sleep medicine for decades. A large number of studies have demonstrated the associations between disease severity as assessed by PSG signals and health outcomes. ${ }^{8-10}$ However, among the hundreds of signals, only very limited parameters, such as the apnea hypopnea index (AHI) and several oxygen desaturation indices, have been verified for clinical application. ${ }^{11}$ These metrics can be reliably collected at a lower cost and with a lower patient burden at home for most patients with SDB. In addition, emerging evidence has demonstrated that polygraphy is not inferior to PSG in specific subgroups of patients, such as those with chronic obstructive pulmonary disease, stroke and congestive heart failure, ${ }^{12-14}$ who were considered unsuitable for home study and also at the greatest risk for poor outcomes related to COVID-19. Considering the possibility of the pandemic to continue in the next several years, the choices of sleep study procedures deserve to be thought out to keep the sleep service running.

PAP therapy is an open system that can generate contact, droplets, and airborne severe acute respiratory syndrome coronavirus 2 (SARS-CoV-2), thereby increasing the risk of transmission of COVID-19. ${ }^{15}$ Similar to sleep studies, changes in the number and mode of PAP titration during the pandemic were related to the national epidemic prevention and control policy and local epidemic conditions. During the initial stage of the outbreak, nearly all sleep centers postponed the in-lab manual titration service, except for urgent requests that were carefully evaluated on a case-by-case basis. This was in line with the results of a European survey, which reported that only one-fifth of centers continued in-lab titration services during the early surge of the pandemic. ${ }^{16}$ However, we also noticed that laboratory-based PAP titration (manual or auto) was still the mainstay PAP initiation strategy during the pandemic. A possible reason may be that the PAP machine was not reimbursed by the basic medical insurance system and that PAP-associated sleep healthcare was not well developed in China. On most occasions, it was difficult to find a professional vendor to provide the PAP service according to the physician's prescription. Considering that patient satisfaction with titration and initial compliance is key to the acceptance and long-term adherence of PAP, ${ }^{17}$ most physicians and patients prefer to perform PAP titration in the hospital, even with autotitration. Previous studies have demonstrated that the homebased strategy (auto CPAP initiation at home followed by polygraphy) is as effective as the laboratory-based strategy in moderate-to-severe patients with a high pretest probability of OSA. ${ }^{18-20}$ The optimal SDB management strategy under different medical service systems warrants further exploration, especially during the COVID-19 pandemic.

Telemedicine, as a method of care delivery, can improve patient access to convenient care. ${ }^{21}$ Given the prevalence of OSA, its high medical and economic burden, poor penetration of diagnosis ( $80 \%$ undiagnosed) ${ }^{22}$ and the limitation of in-person visits that occurred due to the pandemic, it is becoming more important in SDB management during and after the COVID-19 pandemic. In this survey, most of the sleep physicians had a positive attitude toward the prospects of telemedicine in SDB management. However, only about one-fourth of the sleep centers practiced this service, and they were mainly located in relatively underdeveloped areas, with the $\mathrm{C} 2 \mathrm{C}$ form. Telemedicine in China is only in the primary stage, and relevant policies and regulations at the national level are lacking. Unlike medical systems in some other countries, which had very quick responses to expand the coverage 
for telemedicine services, ${ }^{23}$ the number of sleep centers providing this service did not increase significantly during the outbreak. Further studies need to track the outcomes of this new service and explore the suitable subsets of patients and appropriate policies that fit in different medical systems.

While the COVID-19 pandemic has significantly impacted routine operations of the sleep health delivery system, it has also markedly influenced sleep medicine education and training in the surveyed centers. The oneyear sleep medicine fellowship training program has been approved by the Chinese Medical Doctor Association; however, it has not been established in China to date. For the current period, the 3-6-month visiting program is the main training mode. The short-term training program seems to have almost suspended during the outbreak, according to the substantial decline of visiting physicians/technicians in the surveyed centers. A possible explanation is that enrollment for the short-term training program occurs four times annually (February, May, August, and November). Due to the relocation of some medical staff to a more emergent position and the strict human mobility restrictions during the early surge of the outbreak, enrollment in February almost halted in most sleep centers. The long-term impact of the pandemic on sleep medicine training has yet to predict. A more flexible training mode and new educational tool utilizing new technologies should be explored under the circumstance of a continuing pandemic.

Some limitations of the study should be noted. First, this is a national survey among the relatively large sleep centers majoring in SDB management. The disease management strategies may be different among different levels of sleep service programs; therefore, the current data may not precisely represent the whole picture of SDB services in China during the pandemic. In addition, one answer per center may not be enough to provide proper information, and personal interpretation of the questions and the personal biases of the responses should also be considered. Finally, changes in patient volume for SDB diagnosis and management during the pandemic were expressed as percentages rather than actual numbers in the present survey, which may lower the comprehensiveness of the information. As all responses were provided by the medical directors of the sleep centers, we suppose that they could provide relatively accurate information on the overall operational condition of the sleep centers.
In conclusion, the COVID-19 pandemic has greatly challenged the SDB management in China. Polygraphy played a major role in SDB diagnosis during the pandemic; however, home-based SDB management strategies and telemedicine have not been well implemented in China. The second wave of COVID-19 in Beijing almost cut back on recovering SDB services to the early outbreak level, which may be an alert that our medical system is not well prepared for the continuing pandemic. Consequently, this pandemic may give us an impetus to restructure our sleep-health service system to make sleep health services more accessible to patients in need, especially in this pandemic or a post-pandemic era.

\section{Abbreviations}

C2C, center to center; C2P, center to patients; COVID-19, 2019 coronavirus disease; CTS, Chinese Thoracic Society; PAP, positive airway pressure; PSG, polysomnography; SDB, sleep disordered breathing; SARS-CoV-2, severe acute respiratory syndrome coronavirus 2 .

\section{Acknowledgments}

We appreciated all the members of the assembly of sleep disordered breathing of the Chinese Thoracic Society, who responded to this survey and provided support to this investigation (http://www.csrd.org.cn).

\section{Author Contributions}

All authors contributed to data analysis, drafting or revising the article, have agreed on the journal to which the article will be submitted, gave final approval of the version to be published, and agree to be accountable for all aspects of the work. No authors have any financial support related to this study. This study is not involved in any off-label or investigational use. And there is no conflict of interest.

\section{Funding}

This work was supported by research grants from the National Key Research and Development Project (2018YFC1315103) from the Ministry of Science and Technology of China.

\section{Disclosure}

The authors report no conflicts of interest for this work and declare that they have no known competing financial interests or personal relationships that could have appeared to influence the work reported in this paper. 


\section{References}

1. World Health Organization. Coronavirus disease 2019 (COVID-19) situation report - 51.51 1-9; 2020. Available from: https://www.who. int/docs/default-source/coronaviruse/situation-reports/20200311sitrep-51-covid-19.pdf?sfvrsn=1ba62e57_10. Accessed December 31, 2020.

2. Ramar K. The COVID-19 pandemic: reflections for the field of sleep medicine. J Clin Sleep Med. 2020;16(7):993-996. doi:10.5664/ jesm.858011

3. Zhang XL, Xiao Y; assembly of sleep disordered breathing of Chinese Thoracic Society. Expert consensus on sleep study and non-invasive positive airway pressure therapy during the epidemic of coronavirus disease 2019. Zhonghua Jie He He Hu Xi Za Zhi. 2020;43(6):490-495. doi:10.3760/cma.j.cn11214720200309-00283

4. Benjafield AV, Ayas NT, Eastwood PR, et al. Estimation of the global prevalence and burden of obstructive sleep apnoea: a literature-based analysis. Lancet Respir Med. 2019;7(8):687-698. doi:10.1016/ S2213-2600(19)30198-5

5. Lam B, Lam DC, Ip MS. Obstructive sleep apnoea in Asia. Int J Tuberc Lung Dis. 2007;11(1):2-11. PMID: 17217123.

6. Miller R, Englund K. Clinical presentation and course of COVID-19. Cleve Clin J Med. 2020;87(7):384-388. doi:10.3949/ ccjm. 87 a.ccc013

7. Jahrami H, BaHammam AS, Bragazzi NL, et al. Sleep problems during COVID-19 pandemic by population: a systematic review and meta-analysis. J Clin Sleep Med. 2020. doi:10.5664/ jcsm. 8930

8. Zinchuk AV, Jeon S, Koo BB, et al. Polysomnographic phenotypes and their cardiovascular implications in obstructive sleep apnoea. Thorax. 2018;73(5):472-480. doi:10.1136/thoraxjnl-2017-210431

9. Grigg-Damberger M. Why a polysomnogram should become part of the diagnostic evaluation of stroke and transient ischemic attack. $J$ Clin Neurophysiol. 2006;23(1):21-38. doi:10.1097/01.wnp.000 0201077.44102.80

10. Kendzerska T, Mollayeva T, Gershon AS, et al. Untreated obstructive sleep apnea and the risk for serious long-term adverse outcomes: a systematic review. Sleep Med Rev. 2014;18(1):49-59. doi:10. 1016/j.smrv.2013.01.003

11. Patel SR, Donovan LM. The COVID-19 pandemic presents an opportunity to reassess the value of polysomnography. $\mathrm{Am}$ $J$ Respir Crit Care Med. 2020;202(3):309-310. doi:10.1164/ rccm.202005-1546ED
12. Chang $\mathrm{Y}, \mathrm{Xu} \mathrm{L}$, Han F, et al. Validation of the Nox-T3 portable monitor for diagnosis of obstructive sleep apnea in patients with chronic obstructive pulmonary disease. J Clin Sleep Med. 2019;15 (4):587-596. doi:10.5664/jcsm.7720

13. Saletu MT, Kotzian ST, Schwarzinger A, et al. Home sleep apnea testing is a feasible and accurate method to diagnose obstructive sleep apnea in stroke patients during in-hospital rehabilitation. J Clin Sleep Med. 2018;14(9):1495-1501. doi:10.5664/jcsm.7322

14. Pillar G, Berall M, Berry R, et al. Detecting central sleep apnea in adult patients using WatchPAT-a multicenter validation study. Sleep Breath. 2020;24(1):387-398. doi:10.1007/s11325-019-01904-5

15. Lance CG. PAP therapy increases the risk of transmission of COVID-19. Cleve Clin J Med. 2020. doi:10.3949/ccjm.87a.ccc003

16. Grote L, McNicholas WT, Hedner J; ESADA collaborators. Sleep apnoea management in Europe during the COVID-19 pandemic: data from the European Sleep Apnoea Database (ESADA). Eur Respir J. 2020;55(6):2001323. doi:10.1183/ 13993003.01323-2020

17. Wang Q, Ou Q, Tian XT, et al. [Analysis of long-term compliance to continuous positive airway pressure in patients with obstructive sleep apnea]. Zhonghua Yi Xue Za Zhi. 2016;96(30):2380-2384. Chinese. doi:10.3760/cma.j.issn.0376-2491.2016.30.004

18. Berry RB, Hill G, Thompson L, et al. Portable monitoring and auto titration versus polysomnography for the diagnosis and treatment of sleep apnea. Sleep. 2008;31(10):1423-1431.

19. Rosen CL, Auckley D, Benca R, et al. A multisite randomized trial of portable sleep studies and positive airway pressure autotitration versus laboratory-based polysomnography for the diagnosis and treatment of obstructive sleep apnea: the HomePAP study. Sleep. 2012;35 (6):757-767. doi:10.5665/sleep.1870

20. Berry RB, Sriram P. Auto-adjusting positive airway pressure treatment for sleep apnea diagnosed by home sleep testing. J Clin Sleep Med. 2014;10(12):1269-1275. doi:10.5664/jcsm.4272

21. Bruyneel M. Telemedicine in the diagnosis and treatment of sleep apnoea. Eur Respir Rev. 2019;28(151):180093. doi:10.1183/1600 0617.0093-2018

22. Chen X, Wang R, Zee $P$, et al. Racial/ethnic differences in sleep disturbances: the multi-ethnic study of atherosclerosis (MESA). Sleep. 2015;38(6):877-888. doi:10.5665/sleep.4732

23. Greiwe J, Nyenhuis SM. Wearable technology and how this can be implemented into clinical practice. Curr Allergy Asthma Rep. 2020;20(8):36. doi:10.1007/s11882-020-00927-3
Nature and Science of Sleep

\section{Publish your work in this journal}

Nature and Science of Sleep is an international, peer-reviewed, open access journal covering all aspects of sleep science and sleep medicine, including the neurophysiology and functions of sleep, the genetics of sleep, sleep and society, biological rhythms, dreaming, sleep disorders and therapy, and strategies to optimize healthy sleep.
The manuscript management system is completely online and includes a very quick and fair peer-review system, which is all easy to use. Visit http://www.dovepress.com/testimonials.php to read real quotes from published authors. 